\title{
A Comparative Study on Electrochemical Determination of Vitamin C in Liver and Tomato Using Platinum and Glassy Carbon Electrodes (Original Article)
}

\author{
Tsegaye Tadesse ${ }^{1}$, Assefa Sirgawie ${ }^{2}$ \\ ${ }^{1}$ Department of Chemistry, Mizan Tepi University, Tepi, Ethiopia \\ ${ }^{2}$ Department of Chemistry, Addis Ababa Science and Technology University, Addis Ababa, Ethiopia \\ Email address: \\ tsegayeepiphanios@gmail.com (T. Tadesse), assefaserg@yahoo.com (A. Sirgawie)
}

\section{To cite this article:}

Tsegaye Tadesse, Assefa Sirgawie. A Comparative Study on Electrochemical Determination of Vitamin C in Liver and Tomato Using Platinum and Glassy Carbon Electrodes (Original Article). Biochemistry and Molecular Biology. Vol. 2, No. 3, 2017, pp. 25-36. doi: $10.11648 /$ j.bmb.20170203.11

Received: December 12, 2016; Accepted: December 29, 2016; Published: May 27, 2017

\begin{abstract}
Ascorbic acid, a water-soluble vitamin, is the most common electroactive biological compound found in most biological species. The electrochemical oxidation of vitamin $\mathrm{C}$ was investigated at GCE and Pt electrodes in various aqueous solutions in the $\mathrm{pH}$ range of 1 to $5(0.1 \mathrm{M} \mathrm{KCl}$ as a supporting electrolyte) by $\mathrm{CV}$ and DPV. Experimental conditions, for CV: Scan rate of $50 \mathrm{mV} / \mathrm{s}$, Initial potential $-100 \mathrm{mV}$ and Final Potential $1000 \mathrm{mV}$, for DPV: Scan Rate 50mV/s, Pulse amplitude $50 \mathrm{mV}$,Pulse period $125 \mathrm{~ms}$, Initial potential $-100 \mathrm{mV}$ and Final Potential $1000 \mathrm{mV}$. For cyclic voltammetry, Regression equation of $\mathrm{y}=23.4611 \mathrm{X}+13.2489$ for $\mathrm{GCE}$ and $\mathrm{y}=5.19714 \mathrm{X}+13.7071 \mathrm{Pt}$; LOD of $0.0035294 \mathrm{mM}$ for GCE and $0.0176 \mathrm{mM}$ for Pt; LOQ of $0.025519 \mathrm{mM}$ for GCE and $0.085066 \mathrm{mMPt}$; R.S.D of \% 2.76\% for GCE and 4.42\% for Pt. And for DPV Regression equation, $\mathrm{y}=1.201 \mathrm{X}+0.530393$ for GCE andy $=0.0521393 \mathrm{X}+0.506857$ for Pt, R.S.D \% 0.391\% for GCE and $4.969 \%$ for Pt, LOD $0.12412 \mathrm{mM}$ for GCE and $0.22497 \mathrm{mM}$ for Pt and LOQ $0.4137 \mathrm{mM}$ for GCEand $0.7499 \mathrm{mM}$ for Pt. The oxidation peak potential of ascorbic acid were $270 \mathrm{mV}$ and $370 \mathrm{mV}$ for GCE in CV and DPV respectively but for Pt electrode $490 \mathrm{mV}$ for $\mathrm{CV}$ and $370 \mathrm{mV}$ for DPV (versus $\mathrm{Ag} / \mathrm{AgCl}$ reference electrode). The influence of the operational parameters like scan rate, pulse amplitude, pulse period, concentration and $\mathrm{pH}$ on the analytical signal was investigated. The method developed by standard was applied to ascorbic acid assessment in liver and tomato samples. The results of ascorbic acid assessment by DPV were compared to those obtained by CV on both GCE and Pt electrodes.
\end{abstract}

Keywords: Vitamin C, Cyclic Voltammetry, Differential Pulse Voltammetry, Glassy Carbon Electrode, Platinum Electrode, Liver, Tomato

\section{Introduction}

Vitamin $\mathrm{C}$ is a water-soluble vitamin, which means it cannot be stored and humans need a constant, daily supply of it for normal growth and development. Vitamin C's primary function is that of an antioxidant and quencher of a variety of reactive oxygen species. It is necessary for the formation of skin, scar tissue, tendons, ligaments, and blood vessels. Vitamin $\mathrm{C}$ is essential for the healing of wounds and for the repair and maintenance of cartilage, bones, and teeth [1], [2], [3].

The term 'vitamin C' refers to both ascorbic acid and dehydroascorbic acid, since the latter oxidation product is reduced back to ascorbic acid in the body ${ }^{[4]}$. Vitamin $\mathrm{C}$ is the generic descriptor for all compounds exhibiting qualitatively the biological activity of ascorbic acid. The terms L-ascorbic acid and ascorbic acid are both trivial designators for the compound 2,3-didehydro-1-threo-hexano-1,4-lactone, which was formerly known as hexuronic acid. The oxidized form of this compound is called L-dehydroascorbic acid or dehydroascorbic acid [5].

Vitamin C plays a role as a redox cofactor and catalyst in a broad array of biochemical reactions and processes. Vitamin $\mathrm{C}$ is designated as ascorbic acid because of its ability to cure and prevent scurvy. Ascorbic acid comes from the Scandinavian terms, skjoerberg or skorbjugg, and from the English, scarfy or scorby [6]. Vitamin C (chemical names: ascorbic acid and ascorbate) is a six-carbon lactone which is 
synthesized from glucose by many animals. Vitamin $\mathrm{C}$ is synthesized in the liver in some mammals and in the kidney in birds and reptiles. However, several species including humans, non-human primates, guinea pigs, Indian fruit bats, and Nepalese red-vented bulbuls are unable to synthesize vitamin $\mathrm{C}$. When there is insufficient vitamin $\mathrm{C}$ in the diet, humans suffer from the potentially lethal deficiency disease scurvy. Humans and primates lack the terminal enzyme in the biosynthetic pathway of ascorbic acid, l-gulonolactone oxidase, because the gene encoding for the enzyme has undergone substantial mutation so that no protein is produced [3], [7], [8].

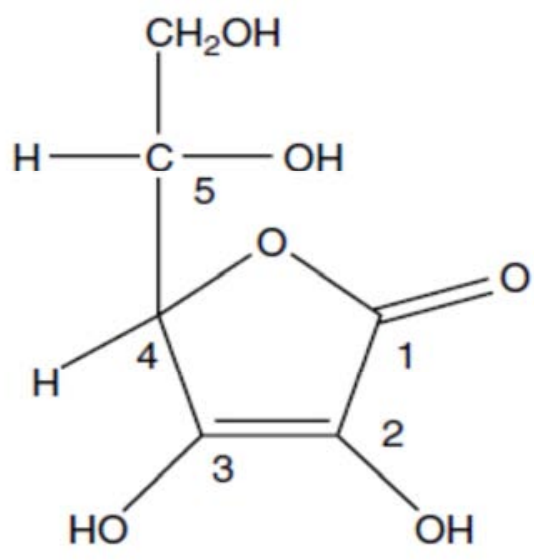

\section{L-Ascorbic acid}

\section{2-oxo-threo-hexono-1,4-lactone-2,3-enediol Vitamin C}

Figure 1. Structure of l-ascorbic acid [5].

\subsection{Physical Properties of Vitamin C}

Ascorbic acid exists as colorless, or white or almost white solid crystalsbut impure samples can appear yellowish.It is odorless or almost odorless. It has a pleasant, sharp acidic taste. It is freely soluble in water and sparingly soluble in ethanol. It dissolves well in water to give mildly acidic solutions. It is practically insoluble in ether and chloroform. Its salts have higher water solubility [52]. All commercial forms except fatty acid esters such as ascorbylpalmitate are insoluble in fats and oils. Ascorbic acid has pKa values of 4.2 and 11.6. Ascorbic acid has a melting temperature of $190^{\circ} \mathrm{C}$ $192^{\circ} \mathrm{C}$ with decomposition ${ }^{4}$. Its crystalline form is monoclinic with mixture of platelets and needles [9].

\subsection{Chemical Properties of Vitamin C}

Ascorbic acid molecule contains four hydroxyl groups and is extremely sensitive to light, heating and the action of oxidizing agents and metal ions. Vitamin $\mathrm{c}$ is readily oxidized, especially in aqueous solutions, by reducing with atmospheric oxygen, and behaves as a two-electron donor

1-Ascorbic acid can oxidize through one- or two-electron transfers. One-electron reductions utilize the transition through the 1-ascorbic acid free radical (semidehydroascorbic acid or monodehydroascorbic acid). Reducing agents and glutathione dehydrogenase convert 1-dehydroascorbic acid back to 1-ascorbic acid, completing the oxidation-reduction cycle. Classic free-radical termination occurs by reduction of a free radical with 1-ascorbate. An electron is transferred to the free radical from ascorbate, producing an ascorbate radical, which acts as a redox agent. The ascorbate radical interacts with itself, forming a 1:1 mixture of 1-ascorbic acid and dehydroascorbic acid. Two-electron reductions occur when transition metals catalyze 1-ascorbic acid oxidation [4], [11].

The most important chemical property of ascorbic acid is the reversible oxidation to semidehydro-L-ascorbic acid and oxidation further to dehydro-L-ascorbic acid. In addition, the proton on oxygen-3 in figure 1 is acidic $\left(p \mathrm{~K}_{1}=4: 17\right)$, which contributes to the acidic nature of ascorbic acid. Degradation reactions of L-ascorbic acid in aqueous solutions depend on a number of factors such as $\mathrm{pH}$, temperature, the presence of oxygen, or metals. Ascorbic acid is not very stable in aqueous media at room temperature [9].

In addition to redox and acid-base properties, ascorbic acid can exist as a free radical. The ascorbate radical is an important intermediate in reactions involving oxidants and ascorbic acid's antioxidant activity. The physiologically dominate ascorbic acid monoanions and dianions have pKs of $4.1\left(p \mathrm{~K}_{1}\right)$ and $11.79\left(p \mathrm{~K}_{2}\right)$, respectively. Rate constants for the generation of ascorbate radicals vary considerably, for example,104-108 $\mathrm{s}^{-}{ }^{1}$. When ascorbate radicals are generated by oxyanions, the rate constants are on the order of 104-107 s-1 by halide radicals, $106-108 \mathrm{~s}^{-}{ }^{1}$, and when generated by tocopherol and flavonoids radicals, 106-108 $\mathrm{s}^{-1}$ [9].
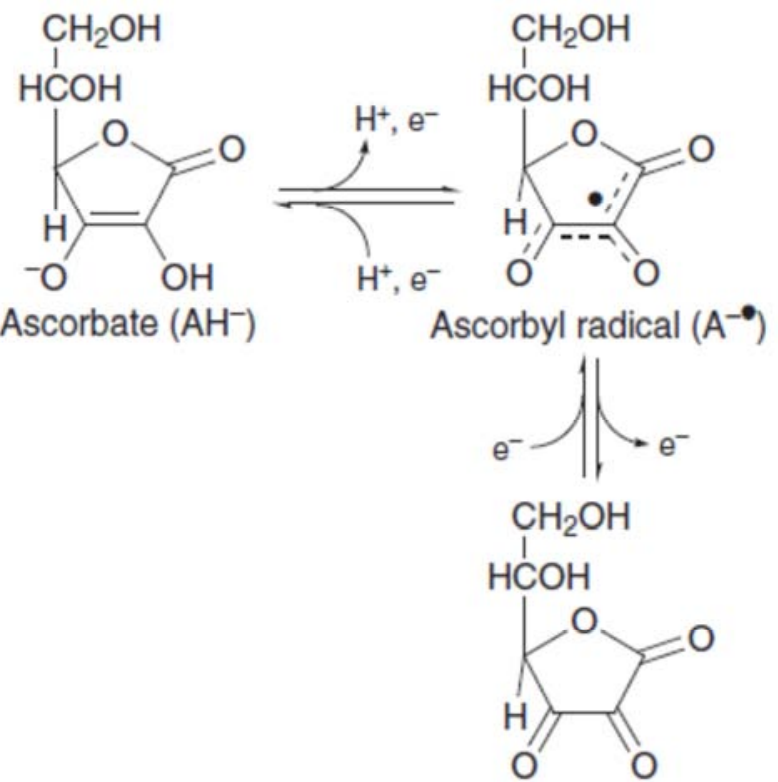

Dehydroascorbic acid

Figure 2. Oxidation of Ascorbate [5].

The spectral properties of 1-ascorbic acid. E1\% $1 \mathrm{~cm}$ values for 1 -ascorbic acid are 695 at $\mathrm{pH} 2.0$ and 940 at $\mathrm{pH}$ 
6.0. Above $\mathrm{pH}$ 5.0, 1-ascorbic acid exists predominantly as the monoanion and has maximal absorption at $265 \mathrm{~nm}$. Undissociated, at more acid $\mathrm{pH}$ levels, maximal absorption occurs at 244-245 nm. Fully dissociated, above $\mathrm{pH} 12.0$, maximal absorption occurs at $300 \mathrm{~nm}$. 1-Ascorbic acid does not fluoresce [4].

Ascorbic acid, a reductone, behaves as a vinylogous carboxylic acid wherein the electrons in the double bond, hydroxyl group lone pair, and the carbonyl double bond form a conjugated system. Because the two major resonance structures stabilize the deprotonated conjugate base of ascorbic acid, the hydroxyl group in ascorbic acid is much more acidic than typical hydroxyl groups. In other words, ascorbic acid can be considered an enol in which the deprotonated form is a stabilized enolate [8], [9].

\subsection{Electrochemistry of Vitamin C}

Vitamin C is the only water-soluble vitamin not assayed microbiologically. Methodology has advanced from the bioassay to instrumentally advanced spectrophotometric, fluorometric, electrochemical, and chemiluminescence methods. Chromatographic procedures, primarily liquid chromatography, and capillary electrophoresis provide excellent means to resolve 1-ascorbic acid, 1-dehydroascorbic acid, and d-isoascorbic acid. These separation techniques used with ultraviolet/visible (UV/visible), fluorescence, or electrochemical detectors provide selective and sensitive means to quantify 1-ascorbic acid and its isomers from complex biological matrices. Liquid chromatography coupled to mass spectrometry (LC-MS) has been used less frequently for vitamin $\mathrm{C}$ analysis compared to its use in other watersoluble vitamin studies [4].

Numerous analytical techniques have been reported in the literature for the determination of vitamin $\mathrm{C}$ in different samples. These include titrimetric [12], [13], fluorometric [14], Flow Injection Photoamperometric [15], Flow electrochemical determination [16], direct injection liquid chromatography [17], high-performance liquid chromatography [18], spectrophotometric [19], [20], [21], [22], Photoelectrochemical [23], amperometric [24-30], Sonovoltammety [31], Electrocatalytic Determination [3237], Electrochemical [38-43]. The vitamin C levels in some biological samples have been reported by several investigators. Although titrimetric methods are simple to use in the determination of vitamin $\mathrm{C}$, difficulties are encountered with commonly used titrants and interferences often occur with colored samples. Electrochemical methods can be useful in the determination of vitamin $\mathrm{C}$ levels in biological samples because ascorbic acid is easily oxidized to dehydroascorbic acid. Electrochemical methods traditionally have found important applications in sample analysis and in organic and inorganic synthesis. Cyclic and differential pulse voltammetry methods are employed in the determination of ascorbic acid levels in different biological samples including fruits, honey, Juices, Tablets, cosmetics, drinks, blood plasma [44-48].

Electrochemical determination of ascorbic acid can be conducted by bare glassy carbon [49], carbon paste [10], gold or platinum $[10,50]$ electrode or chemically modified electrode [51-54] either by cyclic voltammetry or differential pulse voltammetry $[45,57]$.

\section{Objective of the Study}

\subsection{General Objective}

The general objectives of the study is to examine and compare the electrochemical oxidation of vitamin $\mathrm{C}$ in Liver and Tomato on GCE and Pt electrodes.

\subsection{Specific Objective}

The specific objectives are to:

i. Determine vitamin $\mathrm{C}$ content in some selected biological samples using CV and DPV.

ii. Observe the effect of concentration, $\mathrm{pH}$, scan rate, pulse amplitude and pulse period on the electrochemical oxidation of ascorbic acid.

iii. Compare the electrochemical results of vitamin $\mathrm{C}$ in liver and Tomato using GCE and Ptelectrodes.

\section{Experimental Part}

\subsection{Materials and Instrumentation}

BAS 100B, electrochemical analyzer [bioanalytical systems (BAS), USA] connected to a computer was used for voltammetric measurements with three electrode system consisting of working electrode (Glassy carbon, $3 \mathrm{~mm}$ in diameter and Platinum, $2 \mathrm{~mm}$ in diameter), platinum coil wire for auxiliary electrode and $\mathrm{Ag} / \mathrm{AgCl}$ reference electrode. All pH measurements were made with a $\mathrm{pH}$ meter model Metrohm 3305 at ambient temperature of the laboratory. Weight was measured using analytical balance(OHAUS E11140,Switzerland).Other materials include; Spoon, suction filter paper, wash bottle, Mortar with pestle, volumetric flask of different size, graduated test tube and Graduated cylinder.

\subsection{Chemicals and Reagents}

All chemicals and reagents were of analytical grade and were purchased from, Ascorbic acid and $\mathrm{KCl}$ (blulux chemicals ltd., India-New Delhi), Sodium Hydroxide and hydrochloric acid (Fluka-Switzerland), distilled water. Liver sample was purchased from Eyoha Cultural Restaurant and Tomato Sauce from open market in Gondar Town.

\subsection{Electrode Polishing and Electrode Activation}

Both working electrodes were polished prior to each run. Polishing involved using extra powdered alumina powder on the polishing pad and form paste using distilled water followed by a thorough rinse with distilled water. The rinsed electrodes were polished again on a polishing pad to remove any film left and again rinsed thoroughly with distilled water 
and placed immediately in the electrochemical cell. On the other hand platinum auxiliary electrode was immersed in concentrated hydrochloric acid solution in order to remove or dissolve any deposit formed on the counter reaction that decreases the surface area of reaction then rinsed thoroughly with distilled water before use [61].

\subsection{Working Procedure}

$0.1 \mathrm{M} \mathrm{KCl}$ was used as supporting electrolyte which is prepared by dissolving weighted amount of $\mathrm{KCl}$ in distilled water. A stock solution of ascorbic acid $(12 \mathrm{mM})$ was prepared by dissolving an accurate mass of the pure ascorbic acid in appropriate volume of $0.1 \mathrm{M} \mathrm{KCl}$ solution. The working solutions ranging between $2 \mathrm{mM}$ to $12 \mathrm{mM}$ for the voltammetric investigations were prepared by dilution of the stock solution using $0.1 \mathrm{M} \mathrm{KCl}$ supporting electrolyte solution. $0.1 \mathrm{M}$ solutions of hydrochloric acid and sodium hydroxide were prepared by simple dilution process of stock solutions using distilled water, which were used for $\mathrm{pH}$ adjustment.

The volume the analyzed sample was $15 \mathrm{ml}$ and all measurements were performed at home room temperature, using a $0.1 \mathrm{M} \mathrm{KCl}$ solution as supporting electrolyte. For cyclic voltammetry measurements the potential was scanned within the range -100 to $1000 \mathrm{mV}$, with a $50 \mathrm{mV} / \mathrm{s}$ scan rate, in operational parameter influence study scan rate varies from $25-150 \mathrm{mV} / \mathrm{s}$ for both electrodes. For differential pulse was scanned voltammetry measurements the potential was scanned within the range -100 to $1000 \mathrm{mV}$, potential scan rate of $50 \mathrm{mV} / \mathrm{s}$, pulse amplitude of $50 \mathrm{mV}$, pulse width of 25 $\mathrm{ms}$ and pulse period of $125 \mathrm{~ms}$. For the investigation of the influence of the operational parameters on the electroanalytical signal, the pulse amplitude varied between 25 and $150 \mathrm{mV}$, potential scan rate of $50 \mathrm{mV} / \mathrm{s}$ and the pulse period ranged between 75 and $200 \mathrm{~ms}$ for both electrodes.

\subsection{Choice of Solvent}

Since the purpose of this paper is to analyze the level of ascorbic acid in selected biological samples with electrochemical method, it is important to select the most suitable medium which dissolve samples. For electrochemical experiments, the solvent should meet the requirements as followed:

a) Miscibility with samples in order to get homogenous mixture.

b) Good dielectric constant of the solvent and solubility of supporting electrolyte in order to obtain a conductive mixture contained biological sample.

c) Lower toxicity for safe analytical application [68].

For ascorbic acid analysis in different samples different solvents are employed, aqueous solvent [2], [8], [10], Phosphate buffer [3].

\subsection{Calibration Graph for Voltammetric Determination}

For both electrodes under cyclic and differential pulse voltammetry in optimum conditions a linear calibration curve for CV and DPV analysis was constructed in ascorbic acid concentrations range $2 \mathrm{mM}-12 \mathrm{mM}, \mathrm{pH}=1$ to $\mathrm{pH}=5 / 6$ and scan rate $50-150 \mathrm{mV} / \mathrm{s}(\mathrm{CV})$. The purpose of calibration was to optimize the parameters.

\section{Results and Discussion}

\subsection{VoltammetricStudies of a Standard Ascorbic Acid at a Glassy Carbon and Platinum Working Electrodes}

\subsubsection{Cyclic Voltammetric Behavior of Standard Ascorbic Acid at Glassy Carbon and Platinum Electrodes}

In order to understand the electrochemical oxidation process of ascorbic acid occurring on platinum and glassy carbon electrodes; it was studied using cyclic voltammetry.

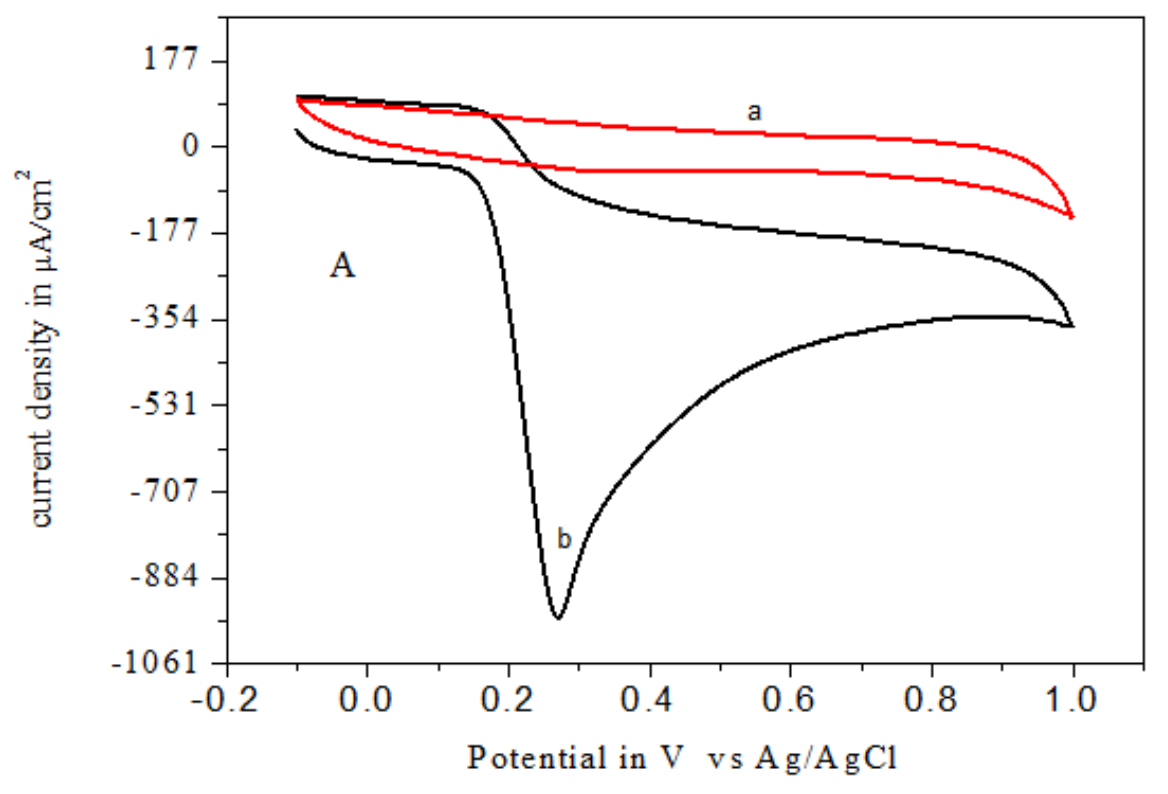

Figure 3. Cyclic voltammogram for Ascorbic Acid. 


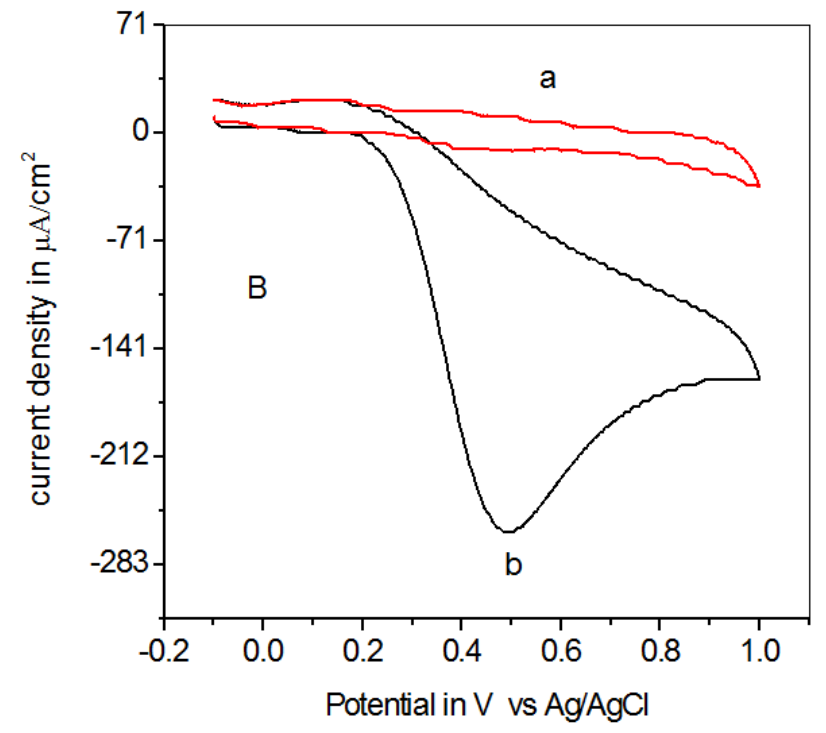

Figure 4. Cyclic voltammogramsof (a) $0.1 \mathrm{M} \mathrm{KCl}$ solution and (b) $12 \mathrm{mM}$ ascorbic acid for GCE $(A)$ under optimized $p H=2$ and Pt working electrode (B) at optimized $\mathrm{pH}=1$.

Experimental results in $\mathrm{pH}$ optimization show that the maximum peak current was obtained in the acidic media $(0.1$ $\mathrm{M} \mathrm{KCl}$ buffer at GCE and Pt electrode) which indicates participation of a proton transfer in the electrode process. Also, the results showed that the shape and intensity of the curves were better in $\mathrm{O} .1 \mathrm{M} \mathrm{KCl}$ buffer $\mathrm{pH}=1$ for $\mathrm{Pt}$ electrode and $\mathrm{pH}=2$ for GCE. Therefore, the $\mathrm{KCl}$ buffer at $\mathrm{pH}=1$ for $\mathrm{Pt}$ and $\mathrm{pH}=2$ for GCE was chosen for the analytical determination.

The voltammograms of $0.1 \mathrm{M} \mathrm{KCl}$ solution and $12 \mathrm{mM}$ ascorbic acid solution at for glassy carbon $(\mathrm{pH}=2)$ and platinum $(\mathrm{pH}=1)$ working electrode are shown in figure 3 .

In both cases no peak current were observed in the voltammograms of the supporting electrolyte in the potential range of -100 to $1000 \mathrm{mV}$ but were observed for $12 \mathrm{mM}$ ascorbic acid solution in the supporting electrolyte in figure 4 for both electrodes at $270 \mathrm{mV}$ at GCE and $490 \mathrm{mV}$ at $\mathrm{Pt}$ electrode. No reduction peak current was observed indicating an irreversible heterogeneous charge transfer in this system. [60] These indicate that ascorbic acid concentration can be measured quantitatively by cyclic voltammetry.

The peak current was directly proportional the rate of electrolysis at the electrode surface. The voltammetric peaks is better defined at the GCE than at the Pt electrode. The peak potential shifts towards more positive values when electrode radius or sphericity of the electrode increases. [60]

i. Effect of concentration

The effect of concentration was studied using cyclic voltammetry on both working electrodes. As can be seen from Figure 5, when the concentration of ascorbic acid increases the peak current also increases successively on both glassy carbon and platinum electrodes.
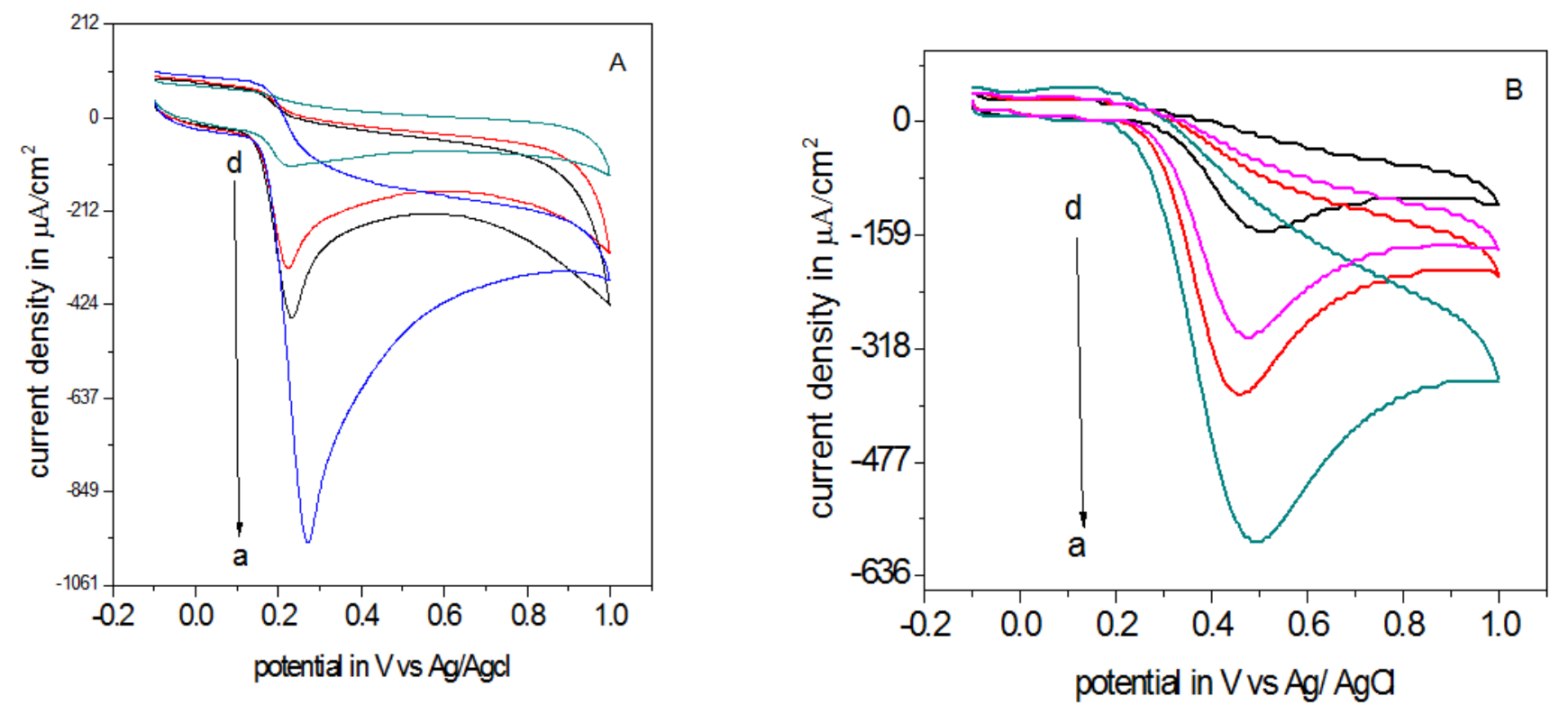

Figure 5. Cyclic voltammograms obtained from different concentrations of ascorbic acid expressed as mM: (a) 12 (b) 10 (c) 8 (d) 6, at (A) GCE $(\mathrm{pH}=2)$ and $(\mathrm{B})$ Pt working electrode $(\mathrm{pH}=1)$ in $0.1 \mathrm{M} \mathrm{KCl}$ buffer and a potential scan rate of $50 \mathrm{mV} / \mathrm{s}$.

The ratio of peak current versus concentration decreases with an increase in concentration of vitamin $\mathrm{C}$ which indicates the process in $\mathrm{KCl}$ is complicated by adsorption phenomena. [59] 

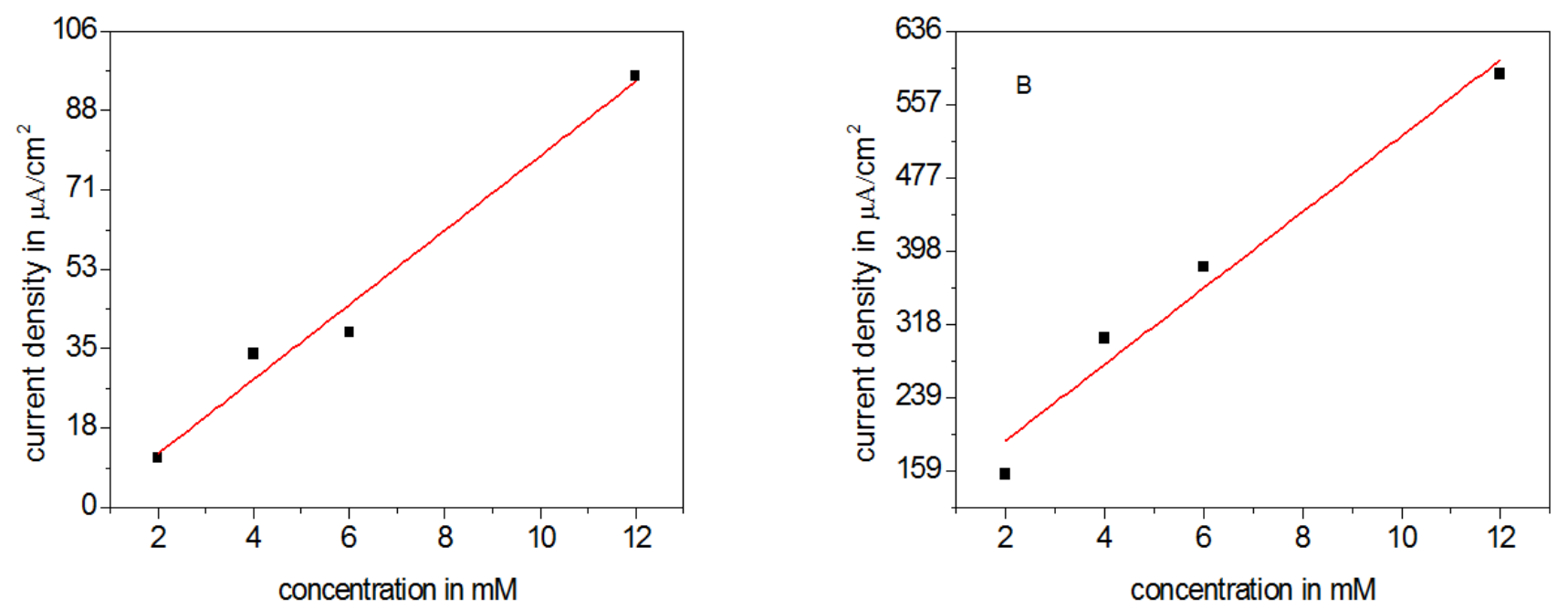

Figure 6. Calibration graph obtained from ascorbic acid determination by cyclic voltammetry at different concentrations expressed as $m M$ using $G C E$ (A) and Pt (B) working electrodes.

The relation between ascorbic acid concentration and cyclic voltammetry peak current is linear and their linear dependence was depicted from calibration curve shown in figure 6 with linear regression equations $\mathrm{y}=23.4611 \mathrm{X}+$ 13.2489 and $\mathrm{y}=5.19714 \mathrm{X}+13.7071$ for GCE and $\mathrm{Pt}$ respectively and correlation coefficients $\left(\mathrm{R}^{2}=0.97241\right.$ for GCE and $\mathrm{R}^{2}=0.95579$ for Pt electrode).

The value calculated for the relative standard deviation R.S.D. were $2.76 \%$, for GCE and $4.42 \%$ for Pt. The values obtained for the limit of detection and the limit of quantification were $0.0035294 \mathrm{mM}$ and $0.0176 \mathrm{mM}$ for GCE and $0.025519 \mathrm{mM}$ and $0.085066 \mathrm{mM}$ for Pt electrode respectively. This is calculated using equation 9 and 10 below.

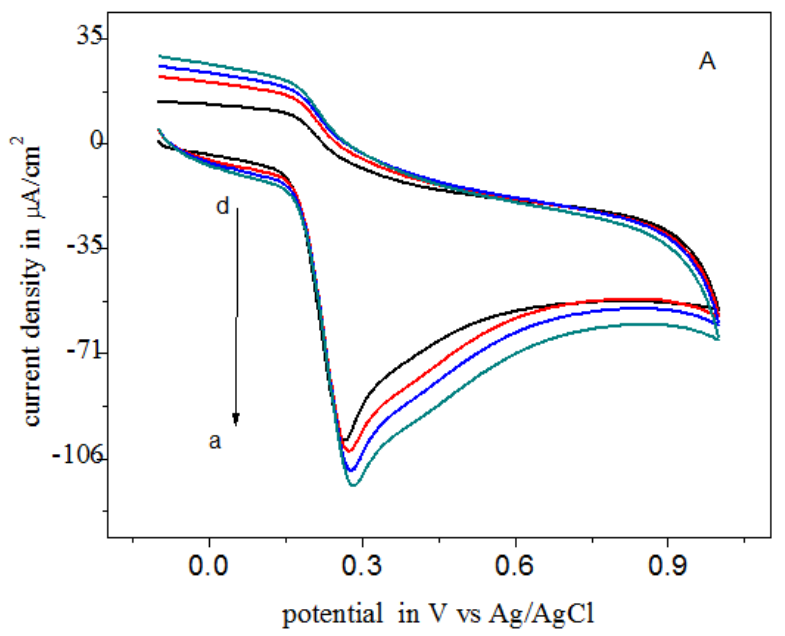

$$
\begin{aligned}
& \mathrm{LOD}=3 \frac{\mathrm{S} . \mathrm{D}}{\mathrm{m}} \\
& \mathrm{LOQ}=10 \frac{\mathrm{S} . \mathrm{D}}{\mathrm{m}}
\end{aligned}
$$

Where, S.D = standard deviation.

$\mathrm{m}=$ slope

ii. Effect of scan rate

Typical cyclic voltammograms of $12 \mathrm{mM}$ ascorbic acid at various scan rates at $\mathrm{GCE}$ and $\mathrm{Pt}$ electrode in $0.1 \mathrm{M} \mathrm{KCl}$ buffer ( $\mathrm{pH}=2$ for $\mathrm{GCE}$ and $\mathrm{pH}=1$ for Pt electrode) is given in figure 7 .

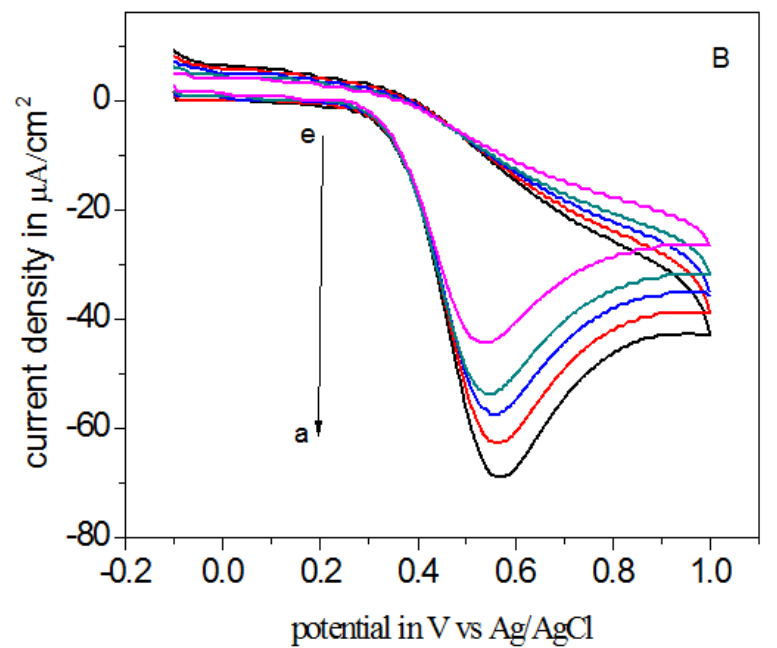

Figure 7. Cyclic voltammograms of $12 \mathrm{mM}$ ascorbic acid in $0.1 \mathrm{M} \mathrm{KCl}$ buffer solution at various scan rates as: (a) 125 , (b) 100 , (c) 75, (d) 50, (e) $25 \mathrm{mVs}-1$ using GCE (A) and Pt (B) electrodes.

The peak potential shifted to more positive values as the scan rate increased as shown in Figure 7, in agreement with the irreversible electrochemical behavior observed for ascorbic acid oxidation in diffusion controlled process. [60] Scan rates are chosen because at this values; Sensitivity was relatively high and the voltammetric curves were well shaped with relatively narrow peak widths. [58] 

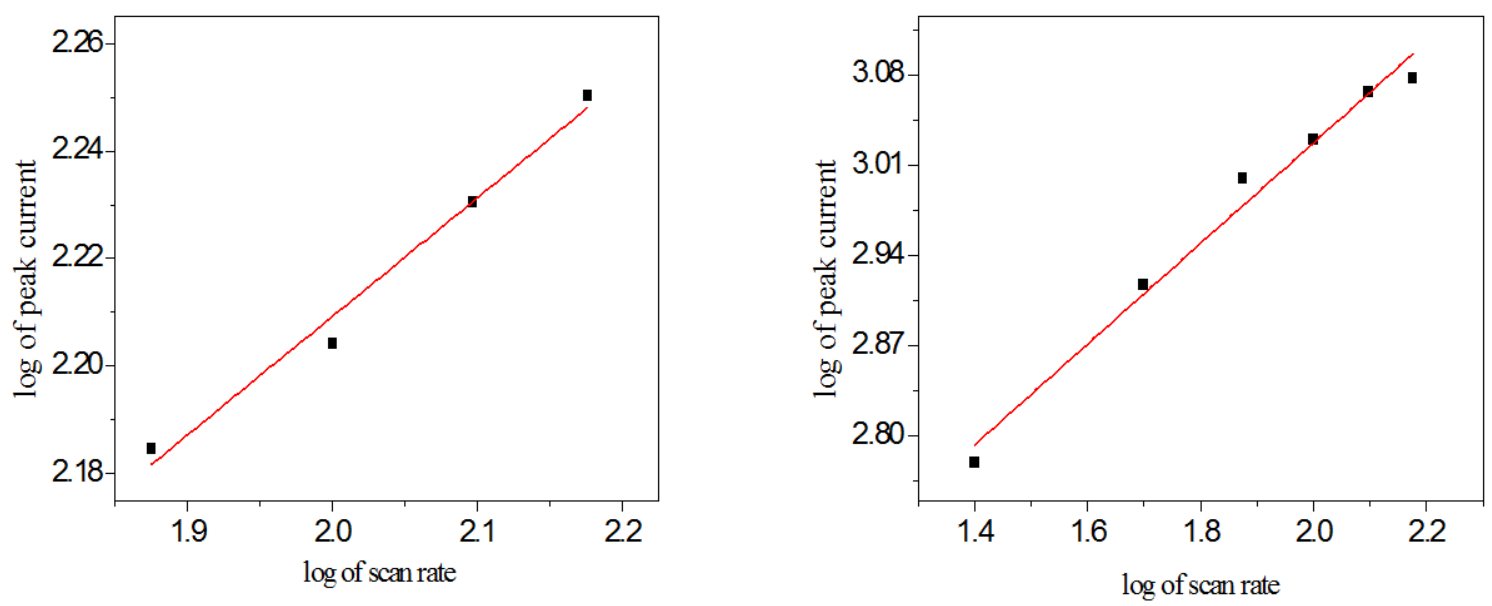

Figure 8. Calibration graph for logarithm of peak current versus logarithm of scan rate for GCE (A) and Pt (B) electrodes.

Plot of the logarithm of peak current versus the logarithm of the scan rate gave a straight linewith correlation coefficient $\left(\mathrm{R}^{2}=0.97571\right.$ for $\mathrm{GCE}$ and $\mathrm{R}^{2}=0.97903$ for $\left.\mathrm{Pt}\right)$ and a slope of 0.22074 for GCE and 0.39085 for Pt electrode, very close to the theoretical value of 0.3 and 0.4 respectively, which is expressed for an ideal reaction of the diffusioncontrolled electrode process [8] [10].

\subsubsection{Differential Pulse Voltammetric Behavior of Standard Ascorbic Acid Using Glassy Carbon and Platinum Electrodes}

The electrochemical oxidation process of ascorbic acid occurring on platinum and glassy carbon electrodes was studied by differential pulse voltammetry technique. The $\mathrm{pH}$ was optimized for DPV method in the electrochemical oxidation behavior of ascorbic acid in a $\mathrm{pH}$ range between $\mathrm{pH}=1$ up to 5 at GCE and Pt electrode in aqueous media. Maximum peak current was obtained in the acidic media $(0.1$ $\mathrm{M} \mathrm{KCl}$ buffer at GCE and Pt electrode) that indicates

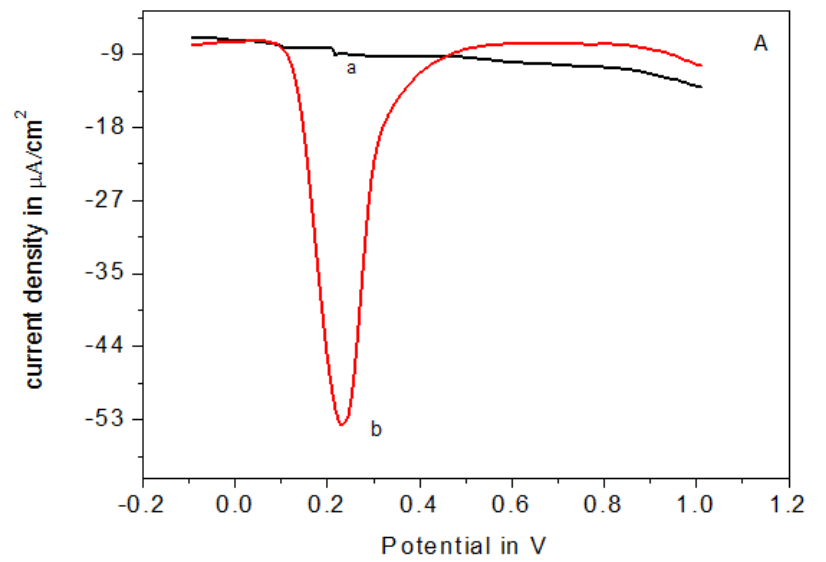

participation of a proton transfer in the electrode process. Also, the experimental results showed that the shape and intensity of the curves were better in $0.1 \mathrm{M} \mathrm{KCl}$ buffer $\mathrm{pH}=$ 1 for GCE and Pt electrode. Therefore, the $\mathrm{KCl}$ buffer at $\mathrm{pH}$ $=1$ for GCE and Pt electrode was chosen for the analytical determination in DPV technique. DPV response was strongly $\mathrm{pH}$ dependent.

The voltammograms of $0.1 \mathrm{M} \mathrm{KCl}$ buffer solution and 12 $\mathrm{mM}$ ascorbic acid solution at $\mathrm{pH}=1$ for glassy carbon and platinum working electrode are shown in figure 9 below. In both cases no peak current were observed in the voltammograms of the supporting electrolyte in the potential range of -100 to $1000 \mathrm{mV}$ but were observed for $12 \mathrm{mM}$ ascorbic acid solution in the supporting electrolyte. No reduction peak current was found indicating an irreversible heterogeneous charge transfer in this system [60]. These indicate that ascorbic acid concentration can be measured quantitatively by differential pulse voltammetry.

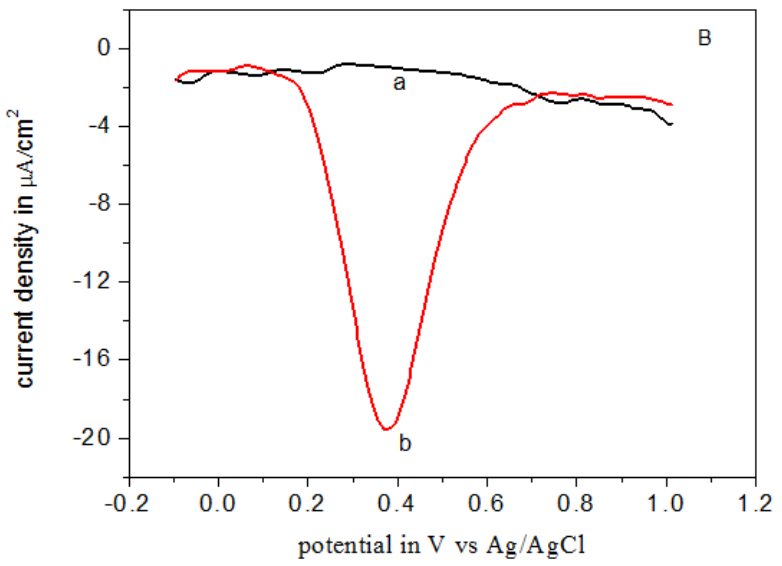

Figure 9. Differential pulse voltammograms of $0.1 \mathrm{M} \mathrm{KCl}$ buffer solution and $12 \mathrm{mM}$ ascorbic acid atoptimized pH $=1$ for GCE (A) and Pt (B) electrode.

Differential pulse voltammetry was used for quantification of vitamin $\mathrm{C}$ since it gives voltammograms in which the peaks are sharper and better defined than those obtained by cyclic voltammetry.

i. Effect of concentration

In figure 10, several differential pulse voltammograms, obtained at GCE and Pt working electrode, for different ascorbic acid concentrations at $\mathrm{pH}=1$ are presented. The peak corresponding to ascorbic acid oxidation appeared at $235 \mathrm{mV}$ and $375 \mathrm{mV}$ (versus $\mathrm{Ag} / \mathrm{AgCl}$ reference electrode) for GCE and Pt respectively. The calibration graph(Figure 11) shows a linear range obtained between 2 and $12 \mathrm{mM}$ 
ascorbic acidand linear regression of $\mathrm{y}=1.201 \mathrm{X}+0.530393$ for GCE and $\mathrm{y}=0.0521393 \mathrm{X}+0.506857$ for Pt electrode, $\left(\mathrm{R}^{2}=0.99609\right.$ for $\mathrm{GCE}$ and $\mathrm{R}^{2}=0.95032$ for $\left.\mathrm{Pt}\right)$.

The value calculated for the relative standard deviation

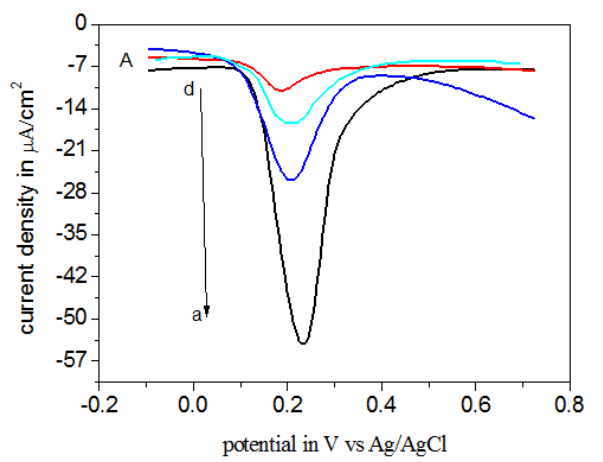

R.S.D. were $0.391 \%$, for GCE and $4.969 \%$ for Pt. The values obtained for the limit of detection and the limit of quantification were $0.12412 \mathrm{mM}$ and $0.4137 \mathrm{mM}$ for GCE and $0.22497 \mathrm{mM}$ and $0.74 \mathrm{mM}$ for Pt electrode respectively.

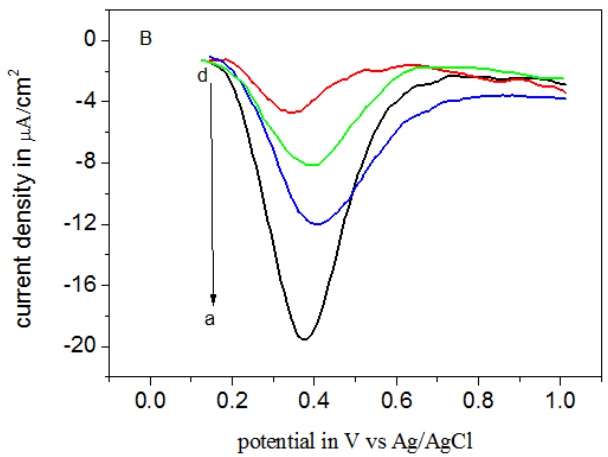

Figure 10. Differential pulse voltammograms obtained with GCE (A) and Pt (B) electrodes for differentascorbic acid concentrations, expressed as mM: (a) 12 (b) 10(c) 8 and (d) 6; experimental conditions: pulse amplitude $50 \mathrm{mV}$, pulse period $125 \mathrm{~ms}$, potential scan rate $50 \mathrm{mV} / \mathrm{s}$.
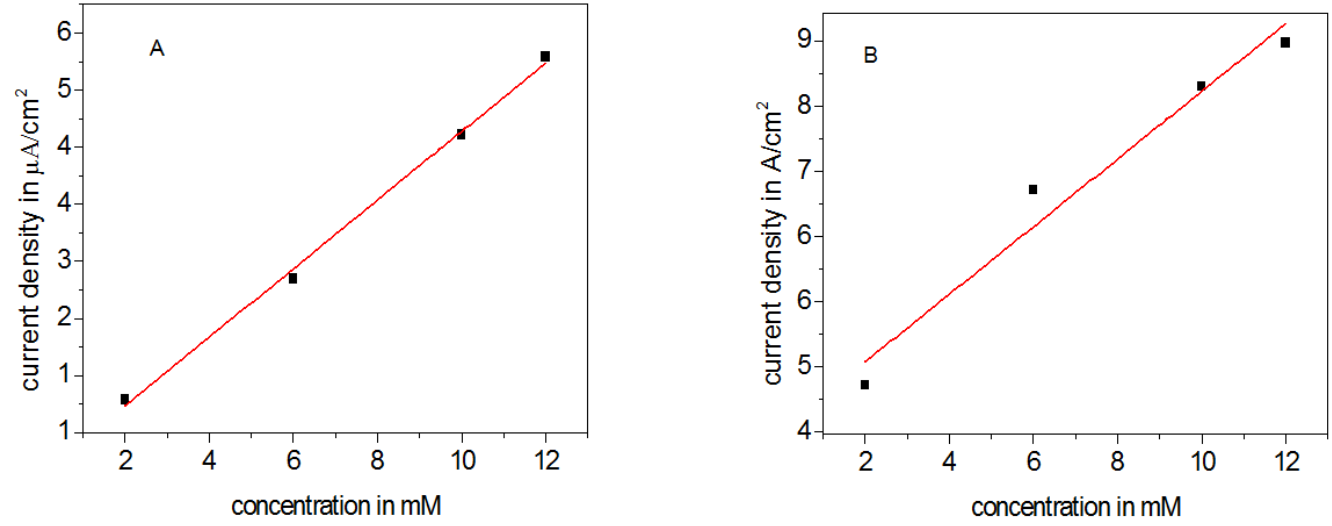

Figure 11. Calibration graph obtained from ascorbic acid determination by DPV at different concentration values using GCE (A) and Pt (B) working electrodes.

ii. Effect of pulse amplitude
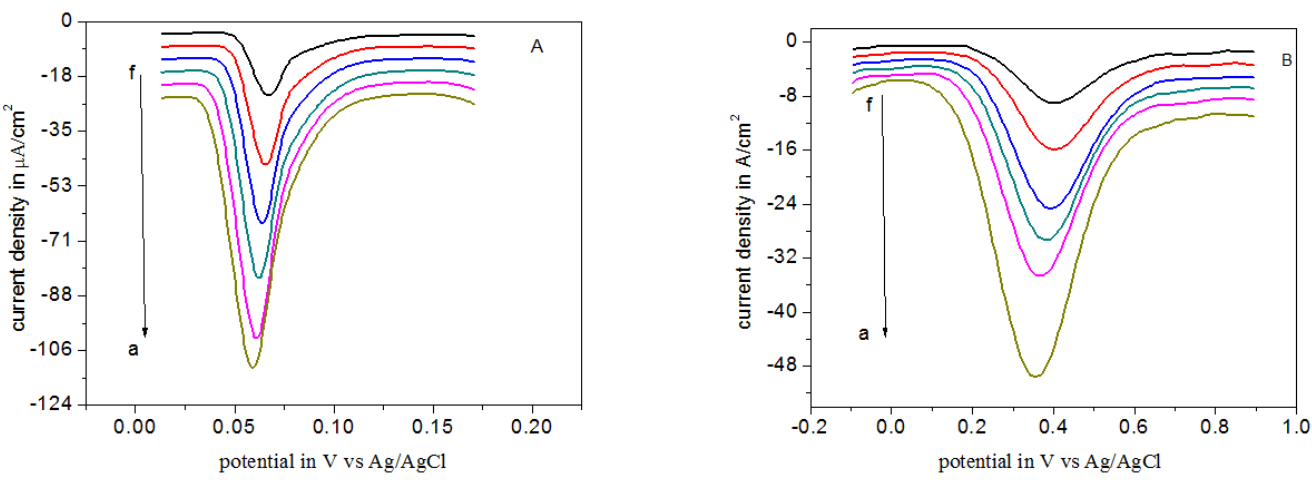

Figure 12. Influence of pulse amplitude of DPV on ascorbic acid determination, using GCE (A) and Pt (B) electrodes; (a) $25 \mathrm{mV}(\mathrm{b}) 50$ $\mathrm{mV}(c) 75 \mathrm{mV}$ (d) $100 \mathrm{mV}$ (e) $125 \mathrm{mVand}$ (f) $150 \mathrm{mV}$; experimental conditions: pulse period 125 ms, potential scan rate $50 \mathrm{mV} / \mathrm{s}$.

For the investigation of the influence of the pulse amplitude for GCE and Pt electrodes (figure 12), the parameter was varied between 25 to $150 \mathrm{mV}$, at $125 \mathrm{~ms}$ pulse period and $50 \mathrm{mV} / \mathrm{s}$ potential scan rate. By analyzing the results presented in figure 4.9 , it can be noticed that the value of the measured current intensity increases with the applied pulse amplitude. The peak height increases with the decrease of the pulse amplitude. An optimum value of $50 \mathrm{mV}$ was chosen for further studies and in real sample analysis at both electrodes because above this value the peak becomes distorted and below this values the peak width becomes large which results peak interpretation difficult. 
iii. Influence of pulse period

For the investigation of the influence of the pulse period (Figure 13) we varied this parameter between 75 and $200 \mathrm{~ms}$, at $50 \mathrm{mV}$ pulse amplitude and $50 \mathrm{mV} / \mathrm{s}$ potential scan rate. The peak height and width increases with the decrease of the

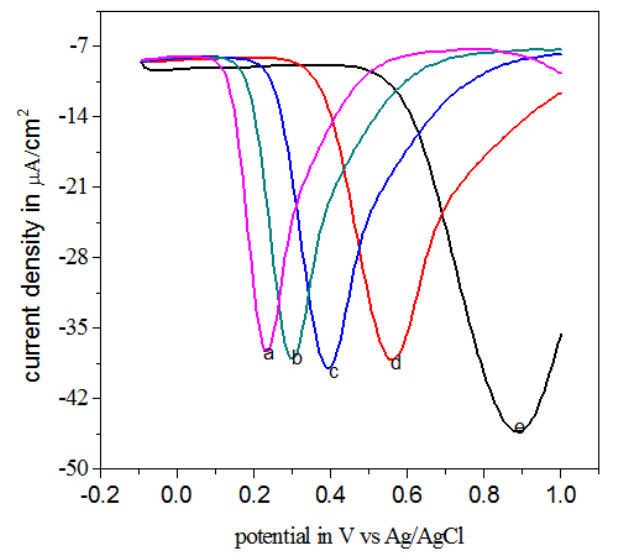

pulse period. The optimum value chosen for further studies was $125 \mathrm{~ms}$. Smaller values of the pulse amplitude were not used, in order to diminish the influence of noise at values of the pulse period below $100 \mathrm{~ms}$, larger values of pulse amplitude result with poor peak resolution.

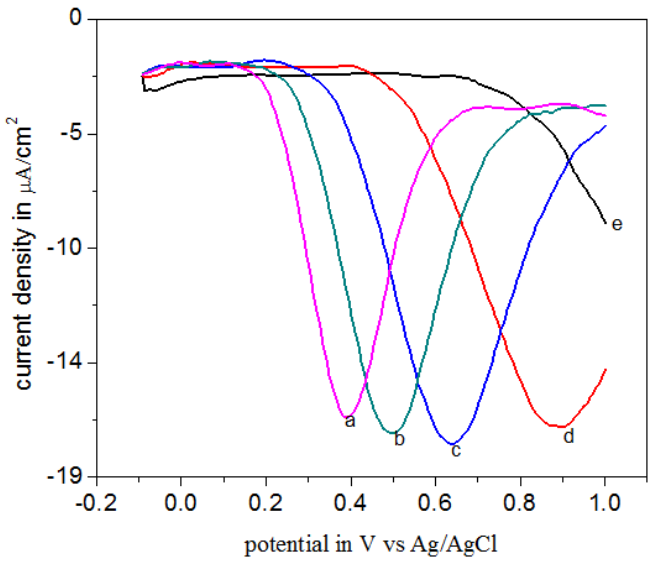

Figure 13. Influence of the pulse period on the analytical response at ascorbic acid determination bydifferential pulse voltammetry, using GCE (A) and Pt (B) electrodes; (a) $75 \mathrm{~ms}($ b) $100 \mathrm{~ms}(\mathrm{c}) 125 \mathrm{~ms}(\mathrm{~d}) 150 \mathrm{~ms}$ (e) $200 \mathrm{~ms}$; experimental conditions: pulse amplitude $50 \mathrm{mV}$, potential scan rate $50 \mathrm{mV} / \mathrm{s}$.

\subsection{Real Sample Analysis}

Biological samples of plant and animal sources were investigated. These include Ox Liver and Tomato Sauce. In the case of liver, the sample was washed with water and milled and minced using mortar and pistil. $5 \mathrm{~g}$ of the homogenized sample was weighted and dissolved in to $25 \mathrm{ml}$ of $0.1 \mathrm{M} \mathrm{KCl}$ by shaking it for 15 minutes. The dissolved sample is then allowed to settle and filtered in order to get a clear solution for analysis using suction filter paper and introduced in to the cell for run. But for tomato $5 \mathrm{~g}$ of the sauce was weighted and the weighted amount is directly dissolved in $0.1 \mathrm{M} \mathrm{KCl}$ solution by shaking it and ready for run. The working procedure employed for standard ascorbic acid solutions was also applied to biological sample analysis by cyclic and differential pulse voltammetry.

The voltammogram of the supporting electrolyte was recorded then a known volume $\left(\mathrm{V}_{\mathrm{u}}\right)$ of unknown concentration $\left(\mathrm{C}_{\mathrm{u}}\right)$ of the investigated sample was added and

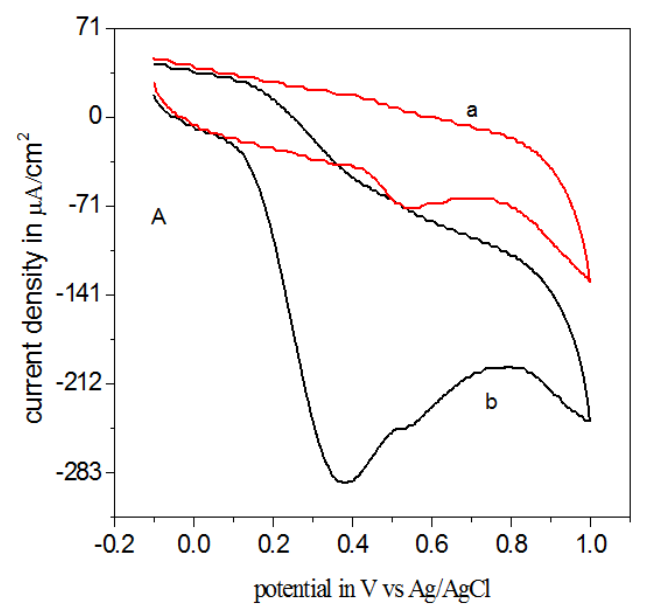

the resulting cyclic and differential pulse voltammetry was recorded and Ip1 was measured then a known volume $\left(\mathrm{V}_{\mathrm{s}}\right)$ of known concentration $\left(\mathrm{C}_{\mathrm{s}}\right)$ of standard was added and the cyclic and differential pulse voltammetry was recorded and $\mathrm{I}_{\mathrm{p} 2}$ was measured. The $\mathrm{C}_{\mathrm{u}}$ can be calculated using the following equation:

$$
C_{u}=\frac{I_{p 1} C_{S} V_{a}}{\left(I_{p 2}\left(V_{u}+V_{s}\right)\right)-I_{p 1} V_{u}}
$$

\subsection{Cyclic Voltammetric Determination of Vitamin C in Liver}

From Figure 14, Vitamin C content of liver can be determined using cyclic voltammetry at GCE (A) and Pt (B) working electrodes. From the voltammograms the amount of Vitamin C in GCE was determined to be $20 \mathrm{mg} / 100 \mathrm{~g}$ and in Pt electrode $16 \mathrm{mg} / 100 \mathrm{~g}$ of liver.

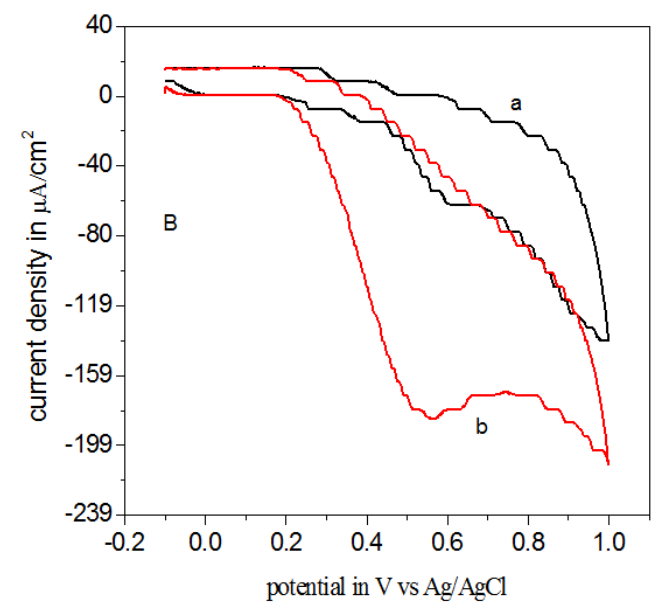

Figure 14. Cyclic voltammogram of liver on GCE (A) and Pt (B) electrode. 


\subsection{Cyclic Voltammetric Determination of Vitamin C in Tomato}

Cyclic voltammograms of tomato at GCE (A) and Pt (B) electrodes show $25.4 \mathrm{mg} / 100 \mathrm{~g}$ and 20.6mg/100g respectively.
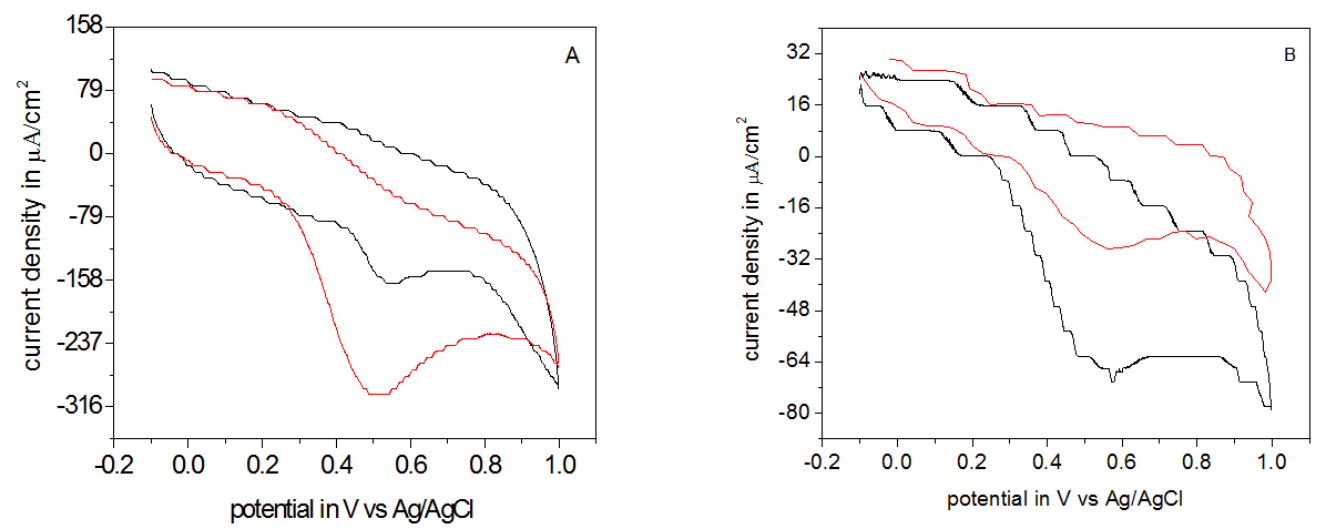

Figure 15. Cyclic voltammograms of ascorbic acid in tomato using GCE (A) and Pt (B) working electrodes.

\subsection{Differential Pulse Voltammetric Determination of Ascorbic Acid in Liver}

Differential pulse voltammograms for liver in GCE (A) and Pt (B) electrodes are shown in figure 16 and the amounts of ascorbic acid in liver sample was calculated as $21.9 \mathrm{mg} / 100 \mathrm{~g}$ and $19.3 \mathrm{mg} / 100 \mathrm{~g}$ respectively.
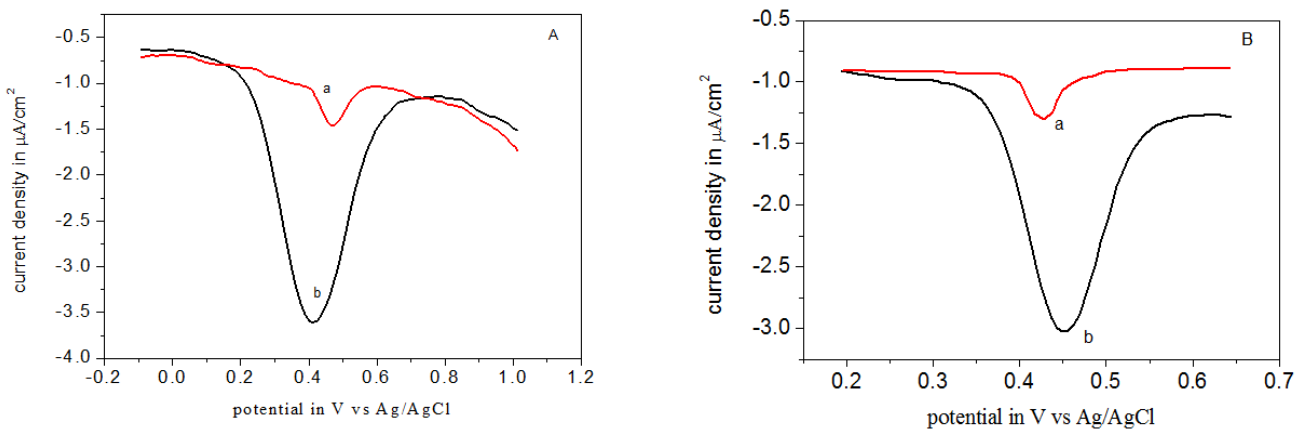

Figure 16. Differential pulse voltammogram for liver using GCE (A) and Pt (B) electrodes under experimental conditions set.

\subsection{Differential Pulse Voltammetric Determination of Ascorbic Acid in Tomato}

Differential pulse voltammogram of tomato under experimental conditions was depicted as in figure 17 and the content of ascorbic acid in tomato by DPV was 26.4 and $21.1 \mathrm{mg} / 100 \mathrm{~g}$ of tomato sauce.
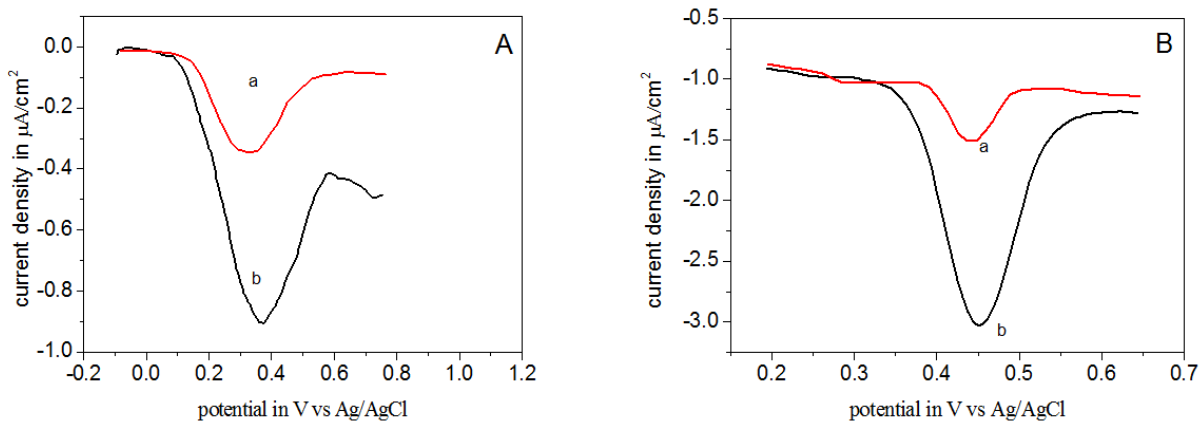

Figure 17. Differential pulse voltammogram for tomato using GCE (A) and Pt (B) under experimental conditions set.

\section{Conclusion and Recommendation}

The electrochemical determination of ascorbic acid can be determined either by cyclic voltammetry or differential pulse voltammetry at glassy carbon and platinum electrodes. The electrochemical oxidation ascorbic acid was irreversible and $\mathrm{pH}$ dependent.

The oxidation peak potential of ascorbic acid were $270 \mathrm{mV}$ and $235 \mathrm{mV}$ for GCE in CV and DPV respectively but for Pt 
electrode $490 \mathrm{mV}$ for $\mathrm{CV}$ and $370 \mathrm{mV}$ for $\mathrm{DPV}$ (versus $\mathrm{Ag} / \mathrm{AgCl}$ reference electrode). Based on the electrochemical oxidation, quantitative determination of ascorbic acid in liver and tomato was studied using cyclic and differential pulse voltammetry techniques.

The result in the quantitative measurements of vitamin $\mathrm{C}$ concentration by $\mathrm{CV}$ and DPV gives higher vitamin $\mathrm{C}$ content in tomato for both electrodes and those for liver is lower. Also, my results show there is a significant difference in the values of vitamin $\mathrm{C}$ quantified between electrode types and method type; glassy carbon gives better result than $\mathrm{Pt}$ electrode in cyclic voltammetry and in differential pulse voltammetry, the difference in the result is due to the sphericity or radius of the electrode.

\section{Acknowledgements}

Above all, I praise God for his uncountable compassions and for everything he did for me with his holly mother St.Marry. I thank my Advisor Dr. Assefa Sirgawie for his unreserved assistance, guidance and very constructive supervision from inception until the accomplishment of the research work.I would like to express my sincerely thanks for MOE for covering the research expenses and sponsorship on my graduate study. I also extend my thanks and appreciation to Gondar University chemistry department and staff members for their cooperation in laboratory arrangements during experimental process of my work. My thanks and appreciation also goes to my colleagues and all my family members.

\section{References}

[1] Kroner Z., Vitamins and minerals, ABC-CLIO, LLC, Santa Barbara, California, 2011.

[2] Yilmaz1 S., Sadikoglu M., Saglikoglu1 G., Yagmur1 S. and Askin G.Int.J.Electrochem.Sci.,2008,3,1534-1542.

[3] Okiei W., Ogunlesi M., Azeez L., Obakachi V., Osunsanmiand M., NkenchorInt G, Int. J. Electrochem. Sci., 2009, 4, 276287.

[4] Eitenmiller R. R., Landen W. O. and Ye L.,Vitamin analysis for the health and food sciences, $2^{\text {nd }}$ ed.,CRC PressTaylor \& Francis Group,2008.

[5] Ball M. F. G., Vitamins: Their role in the human body, Blackwell publishing, 2004.

[6] Combs F. G., The vitamins: fundamental aspects innutrition and health, $3^{\text {rd }}$ ed, Elsevier Academic Press, 2008.

[7] WHO, Vitamin and mineral requirements in human nutrition, $2^{\text {nd }}$ ed., World HealthOrganization and Food and Agriculture Organization of the United Nations, 2004.

[8] Esch R. J., Friend R. J. and Kariuki K. J., Int. J. Electrochem. Sci., 2010,5,146-1474

[9] Mccormick B. D., Rucker B. R., Suttie W. J., and Zempleni J., Hand book of vitamins, $4^{\text {th }}$ ed. CRC Press Taylor \&Francis
Group, 2007.

[10] Pisoschi A. M., Pop A., Negulescu G. P. and Pisoschi A.,Molecules, 2011, 16, 1349-1365.

[11] http://www.umm.edu/altmed/articles/vitamin-c000339.htm\#ixzz1wfkr4sQR,May13, 2012.

[12] Izuagie A.A. and Izuagie F.O.,Research Journal of Agriculture and Biological Sciences, 2007,3,367-369.

[13] Okiei W., Ogunlesi M., Azeez L., Obakachi V., Osunsanmi M. and Nkenchor G., Int. J. Electrochem. Sci., 2009,4,276-287.

[14] Yang J., Mab Q., Hung F., Sun L. and Dong J.,Analytical letters, 1998, 31, 2757-2766.

[15] Dilgin Y. andNis G., Analytical Letters,2006,39,451-465.

[16] Florou A. B., Prodromidis M.I., Karayannis M.I. and Tzouwara-Karayanni S. M., Analytica Chimica Acta, 2000, $409,113-121$.

[17] Lopes P., Drinkine J., Saucier C. and Glories Y., Analytica Chimica Acta, 2006,555, 242-245

[18] Hu L., Li L., Luo Z., Yang J. and Liu W., Journal of Chromatographic Science 2012, 50,102-107

[19] Kesic A., Mazalovic M., Crnkic A., Catovic B., Hadzidedic S., Dragosevic G., Eu. J. Sci. Research, 2009, 32, 95-101.

[20] Revanasiddappa H. D. and Veena M. A., E-Journal of Chemistry, 2008,5,10-15.

[21] Mustafa O., Kubilay G., Burcu B. and Resat O.,Analytica Chimica Acta, 2007,588,88-95.

[22] Pisoschi A. M., Cheregi M. C. and Danet A. F., Molecules, 2009, 14, 480-493.

[23] Cooper J. A., Wu M. and Compton R. G., Anal. Chem. $1998,70,2922-2927$

[24] Babu T., Suneesh P., Ramachandran T. and Nair B., Analytical Letters, 2010, 43, 2809-2822.

[25] O'Connell P., Gormally C., Pravda M., and Guilbault G., AnalyticaChimicaActa, 431, 2001,239-247

[26] Fei J., Luo L., Hu S., Gao Z.,Electroanalysis, 2004,16,319323.

[27] Nalini B. and Narayanan S., AnalyticaChimicaActa, 2000, 405, 93-97.

[28] Pournaghi-Azar M. H., Razmi-Nerbin H., and Hafezi B., Electroanalysis, 14, 2002, 206-2012.

[29] Arvand M., Sohrabnezhad S.,Mousavi M.,Shamsipur M., M.Zanjanchi, Analytica Chimica Acta,491,2003,193-201

[30] Razmi H. and Harasi M., Int. J. Electrochem. Sci., 2008,3,8295.

[31] Akkermans R. P., Wu M., Bain C. D., Fidel-Sua'rez M., and Compton R. G., Electroanalysis, 1998, 10,613-620.

[32] Tavakkoli N., Nasrollahi S. and Vatankhah G., Electroanalysis, 2012, 24, 368-375.

[33] Khorasani-Motlagh M. and Noroozifar M., Turk J Chem, 2004, 28, 369-378. 
[34] Yu A. and Chen H., Analytica Chimica Acta, 1997, 344, 181185.

[35] Ensafi A. A., Analytical letters, 2003, 36, 591-604.

[36] Raoof J., Ojani R., and Beitollahi H., Int. J. Electrochem. Sci., $2007,2,534-548$.

[37] Surya A., Murthy N. and Sharrna J.,Electrounalyis, 1997, 9,726-729.

[38] Ernst H. and Knoll M., AnalyticaChimicaActa, 2001,449,129134.

[39] Gu H., Yu A., and Chen H.,Analytical letters,2001, 34,23612374.

[40] Sun L.,Zhang J., and Liu K.,Analytical Letters, 2007,40,30503059 .

[41] Li1Y. and Zhan S.,J.Dispersion Sci. and Tech., 2008,29,14211425

[42] Ngai K. S., Tan W. T., Zainal Z., Zawawi R. M., and Zidan M., Int. J. Electrochem. Sci., 2012,74210-4222.

[43] Goh1J. K., Tan W. T., Lim F. T., and Maamor N. A. M.,The Malaysian J. of Anal. Sci., 2008, 12,480 - 485.

[44] Hoyle C. H. V. and Santos J. H., Int. Food Research Journal, 2010, 17, 937-946.

[45] Bruna C., Medeiros R. A.,Romeu C. R., and Fatibello-Filho O., Electroanalysis, 2010, 22,1717-1723.

[46] Chang M. and Chang C., J. Food and Drug Analysis, 2005, $13,205-211$.

[47] Sartori E. R. and Fatibello-Filho O., Electroanalysis, 24, 2012, $627-634$.

[48] Bagheri A., Emami F., and Nateghi M.R., Analytical Letters, 1997, 30, 2023-2028.

[49] Ly S. Y., Chae J. I., Jung Y. S., Jung W. W., Lee H. J.and Lee S. H., Nahrung/Food48, 2004, 201-204.

[50] Ernst H. and Knoll M., AnalyticaChimicaActa, 2001, 449, 129-134.

[51] Zidan M., Tee T. W., Abdullah A. H., Zainal Z., Goh K. J., Int. J. Electrochem. Sci., 2011, 6, 289-300.
[52] Neto A. C. R., Pires R. F., Malagoni R. A. and Franco M. R., Jr., J. Chem. Eng., 2010, 55, 1718-1721.

[53] Gaoa Z., Siow K. S., Adeline N. and Zhangb Y., Analytica Chimica Acta 1997, 343, 49-57.

[54] Shankar S. S., Swamy B. E. K., Chandra U., Manjunatha J. G. and Sherigara B.S., Int. J. Electrochem. Sci., 2009, 4, 592601.

[55] Pisoschi A. M., Danet A. F. and Kalinowski S., J. Automated Method. and Manage. ment in Chem., 2008, 2008, 1-8.

[56] Kilmartin P. A., Zou H., and Waterhouse A. L., J. Agric. Food Chem., 2001, 49, 1957-1965.

[57] Radovan C., Cofan C. and Cinghitaa D, Electroanalysis, 2008, 20, 1346-1353.

[58] D. A. Skoog, J. J. Leary, Principles of instrumental analysis, 4th ed., 1992, New York.

[59] H. H. Girault, Analytical and physical electrochemistry, 2004, EPFL Press.

[60] A. J. Bard and L. R.Faulkner, Electrochemical methods: fundamentals and applications, $2^{\text {nd }}$ ed., 2001, John Wiley \& Sons Ltd.

[61] J. Wang, Analyticalelectrochemistry, $2^{\text {nd }}$ Ed., 2000, John Wiley \&Sons LTD.

[62] F. G. Thomas and G. Henze, Introduction to Voltammetric Analysis Theory and Practice, 2001, CSIRO publishing.

[63] R. Gulaboski and C. M. Pereira, Handbook of Food Analysis Instruments, 2008, Otles.

[64] F. Scholz, Electroanalytical Methods Guide to Experiments and Applications, $2^{\text {nd }}$ Ed, 2010, Springer-Verlag Berlin Heidelberg.

[65] R. W. Heinemanand T. P. Kissinger, Laboratory techniques in electroanalytical chemistry, $2^{\text {nd }}$ ed., Marcel Dekker, inc., Madison Avenue, New York, 1996.

[66] P. Monk, Fundamentals of electroanalytical chemistry, 2001, John Wiley \&Sons LTD.

[67] C. G. Zoski, Handbook of Electrochemistry, 2007, Elsevier.

[68] Coatanea M., Darchen A. and Hauchard D., Sensors and accutators, 2001, 76, 539-547. 